\title{
Morphology in the total electron content under geomagnetic disturbed conditions: results from global ionosphere maps
}

\author{
Zhao Biqiang ${ }^{1}$, Wan Weixing ${ }^{1}$, Liu Libo ${ }^{1}$, and Mao Tian ${ }^{1,2,3}$ \\ ${ }^{1}$ Institute of Geology and Geophysics, Chinese Academy of Sciences, Beijing 100029, China \\ ${ }^{2}$ Wuhan Institute of Physics and Mathematics, CAS, Wuhan 430071, China \\ ${ }^{3}$ Graduate School of Chinese Academy of Sciences, Beijing, China
}

Received: 10 January 2007 - Revised: 8 June 2007 - Accepted: 27 June 2007 - Published: 30 July 2007

\begin{abstract}
Using 8-year global ionosphere maps (GIMs) of TEC products from the Jet Propulsion Laboratory (JPL), we make a statistical study on the morphology of the global ionospheric behaviors with respect to the geomagnetic disturbances. Results show that the behaviors of TEC during geomagnetic storm present clear seasonal and local time variations under geomagnetic control in a similar way as those of $N m$ F2 (Field and Rishbeth, 1997). A negative phase of TEC occurs with high probability in the summer hemisphere and most prominent near the geomagnetic poles, while a positive phase is obvious in the winter hemisphere and in the far pole region. A negative storm effect toward lower latitudes tends to occur from post-midnight to the morning sector and recedes to high latitude in the afternoon. A positive storm effect is separated by geomagnetic latitudes and magnetic local time. Furthermore, ionospheric responses at different local time sectors with respect to the storm commencement shows very different developing processes corresponding to the evolution of the geomagnetic storm. A daytime positive storm effect is shown to be more prominent in the American region than those in the Asian and European regions, which may suggest a longitudinal effect of the ionospheric storm.
\end{abstract}

Keywords. Ionosphere (Ionospheric disturbances; Particle precipitation) - Magnetospheric physics (Storms and substorms)

\section{Introduction}

Geomagnetic storm can induce strong disturbances in the Fregion of the ionosphere. These perturbations involve large enhancements and depletions of the electron density at the F2 region during periods termed as positive and negative ionospheric storm phases, respectively. The distinction be-

Correspondence to: Zhao Biqiang

(zbqjz@mail.iggcas.ac.cn) tween positive and negative ionospheric storms represents the simplest possible classification. Actually, the morphology of the ionospheric storm is very sophisticated. Earlier work from Matsushita (1959) showed that an ionospheric storm, occurring in the F2 region, is manifested in the following forms: (1) the short positive phase lasts longer with decreasing latitude, followed by a prolonged negative phase that is stronger with increasing latitude; (2) when the positive phase presents a noticeable local time component, its maximum amplitude occurs near 18:00 LT at subauroral latitudes, earlier at higher latitudes, and later at lower latitudes; and (3) the influence of the season is to have positive storms more pronounced in winter and negative storms in summer. Then later, Prölss et al. (1991) summarized the magnetic storm effects observed in the winter hemisphere at subauroral latitudes which manifest an impressive complexity of the ionospheric storm. The following five disturbance forms have been distinguished: (1) a sudden increase in the ionization density with an uplift of the F layer which is most pronounced in the noon/afternoon sector; (2) positive storm effects which may last a whole day and cover the whole range of middle latitudes; (3) positive storm effects with strongly fluctuating intensity appearing at night; (4) long-duration negative storm effects which prevail in the morning sector; and (5) steep density drop which is typically observed in the afternoon/evening sector. The ionospheric storm behavior in the low latitude and equatorial region is also diversified depending on the equatorial ionization anomaly (EIA) response to different types of disturbance electric fields and disturbance winds (Abdu et al., 1991).

However, most conclusions or results in the case studies or statistical analyses are dealing with the ionosphere's peak electron density $(N m \mathrm{~F} 2)$ derived from ionosonde data. For example, Szuszczewicz et al. (1998) reported on a study of 3 intense ionospheric storms in September, 1989. The SUNDIAL network of 57 ionosondes was used to observe the global response of $h m \mathrm{~F} 2$ and $N m \mathrm{~F} 2$. The negative storm

Published by Copernicus Publications on behalf of the European Geosciences Union. 
phase was dominant; it began at night and co-rotated to the dayside. The F2 peak heights $h m \mathrm{~F} 2$ responded quickly, suggesting the importance of electric fields. Field and Rishbeth (1997) applied the AC/DC analysis technique of Rodger et al. (1989), which separates the $N m \mathrm{~F} 2$ storm changes $\ln \left(N m \mathrm{~F} 2_{\text {storm }} / N m \mathrm{~F} 2_{\text {quiet }}\right)$ into a mean (DC) component and a local time component (AC), to over 20 years worth of data from each of the 53 stations between $70^{\circ} \mathrm{N}$ and $80^{\circ} \mathrm{S}$. Their results showed that $N m \mathrm{~F} 2$ is enhanced in winter compared to equinox and summer. Maxima occur at 15-20 local time (LT), except near the magnetic equator. Field et al. (1998) extended the analysis of Field and Rishbeth (1997) by carrying out runs of the CTIP model and comparing the results with ionosonde data. The model results were plotted vs. storm time, latitude, and longitude, so a complete picture of the simulated storms was obtained. Results support the idea that composition changes can explain both the negative phase and the longer duration positive storm effects through upwelling and downwelling which produces changes in $\mathrm{O} / \mathrm{N} 2$ at fixed pressure levels. However, $N m \mathrm{~F} 2$ changes at middle latitudes during the first $20 \mathrm{~h}$ of the storm time were not as well correlated with composition changes, so the initial positive phase seems to be dynamically controlled. The widespread positive storm effects seen at low latitudes were attributed to composition changes, produced by the downwelling part of the storm circulation. In the auroral zone, equatorward expansion of particle precipitation causes enhancements in $\mathrm{Nm} \mathrm{F} 2$, or trough infilling, as the subauroral trough minimum moves equatorward.

Although the global network of sounding stations has greatly contributed to our current understanding of ionospheric structure and behavior, the ionosonde technique has its limitations. It is well known that during the solar and geomagnetically disturbed conditions, severe absorption, spreading, and oblique echoes often cause ionograms to be nearly impossible to scale. However, many of the problems with $\mathrm{F}$ region ionosonde measurements do not occur when total electron content (TEC), defined as the integral with height of an $\mathrm{Ne}(\mathrm{h})$ profile, is used. Early investigations of storm TEC behavior were through the records of the Faraday rotation of VHF signals from the geostationary satellites. The local time and seasonal variations of positive and negative ionospheric storm effects were seen clearly in the pioneer comprehensive studies of TEC at multiple locations by Mendillo and Klobuchar (1975), Davies (1980), Essex et al. (1981) and Titheridge and Buonsanto (1988). A limitation of the method based on analyzing VHF signals from geostationary satellites is its inability to make measurements globally. Recently, a powerful technique has been developed for deriving global ionospheric maps (GIMs) of TEC by analysis of dual-frequency signals from multiple GPS satellites, which are received by a large global network of receivers (Ho et al., 1997; Mannucci et al., 1998). Since then, GIMs have increasingly become a powerful ionospheric diagnostic tool in studies of ionospheric behavior, particularly under dis- turbed conditions (Ho et al., 1996; Pi et al., 1997; Buonsanto et al., 1999; Aponte et al., 2000; Afraimovich et al., 2002; Vlasov et al., 2003; Kil et al., 2003). These studies show numerous positive and negative storm features which have been observed in $N m \mathrm{~F} 2$, including auroral/subauroral enhancements, dayside mid-latitude enhancements, TID/TAD, latitudinal structures, negative phase depletions, and intensified equatorial "fountain" effects, and so on. TEC becomes the parameter most often used in ionospheric storm studies because of its network of widespread GPS receivers. Furthermore, as an assistant observation combined with the other ground- and space-based measurements, TEC can provide information about the topside ionosphere and plasmasphere. Foster et al. (2002) found the features of plumes of greatlyelevated TEC in northern America to be associated with the erosion of the outer plasmasphere in the dusk sector, which manifests the "peeling away" process of the plasmasphere in the afternoon quadrant to the northward and dayside sector. Yizengaw et al. $(2005,2006)$ used the GPS TEC, as well as a tomographic reconstruction technique to reveal the different behaviors in the bottomside and topside ionosphere during the intense ionospheric storm.

In this paper, 8-year TEC GIMs were used for the first time to derive the global morphology of the TEC storm characteristics. Different from the previous study, we consider not only the storm effect but also include the substorm effect with enough intensity. Through the cross-correlation function analysis, statistical results of the global negative storm effect and the positive storm effect are obtained. Then we investigate the evolutionary behavior of the ionospheric responses to magnetic disturbances under different storm commence local times. Results show that the ionospheric response in the different local time sectors and different longitudes displays a very different developing process, corresponding to the evolution of the magnetic storm.

\section{Data selection and process}

In May 1998, International GNSS Service (IGS), where GNSS is Global Navigation Satellite Systems, created the Ionosphere Working Group (Feltens and Schaer, 1998), and soon after five different centers started computing and making available several GPS-derived ionospheric products, mainly two-dimensional, world-wide grids of vertical total electron content (VTEC) and differential code biases (DCBs) for every satellite and many receivers in the network. To make feasible interchanges and comparisons, the so-called IONEX (Ionosphere Map Exchange) standard format was established (Schaer et al., 1998).

Data we used is the JPL-provided IONEX file, that spans from 1 September 1998 to 31 December 2006 (http://cddis. gsfc.nasa.gov). Before day 307, 2002 the daily IONEX file includes 12 VTEC maps, starting from 01:00 UT to 23:00 UT, due to the fact that each daily file contains 
ionospheric information covering not only 22 but $24 \mathrm{~h}$. The new daily file includes 13 VTEC maps, starting from 00:00 UT to 24:00 UT, in order to facilitate the data interpolation. This version of TEC maps is produced routinely at JPL using data from up to 100 GPS sites of the IGS and other institutions. The VTEC is modeled in a solar-geomagnetic reference frame using bi-cubic splines on a spherical grid. A Kalman filter is used to solve simultaneously for instrumental biases and VTEC on the grid (Pi et al., 1997; Mannucci et al., 1998). Each map is then transformed into an Earth-fixed reference frame with geographic longitude ranging from $-180^{\circ}$ to $180^{\circ}\left(5^{\circ}\right.$ resolution) and latitude from $-87.5^{\circ}$ to $87.5^{\circ}\left(2.5^{\circ}\right.$ resolution). For us, $15^{\circ}$ separation in longitude is enough to present the longitude information. An hourly value is obtained using a linear interpolation.

The storm time change of the ionospheric TEC is defined as

$$
\mathrm{RTEC}=(\mathrm{TEC}-\mathrm{TECq}) / \mathrm{TECq} .
$$

We choose a smooth 27-day median value as TECq. That means the 24-hourly median values were obtained in each cell within the 27-day window and assigned to the central 14th day. Then the window was sliding forward one day and again the new hourly medians were assigned to the next central day. Repeating the procedure, median values were obtained for each cell from 16 September 1998 to 31 December 2006. The advantage of employing the 27-day window smooth medians is to remove diurnal variation and the trend with a period longer than 27 days, for example, the annual and semiannual component. It should be mentioned that this method also does not do a good job whenever the magnetic activity is high throughout the 27-day interval considered.

In the present analysis, by selecting the 27-day window for medians, we actually transfer the 27-day periodicity from measured TEC to its relative deviation RTEC. To remove this periodicity from the relative deviation RTEC, we follow the procedure of Kutiev et al. (2005) by approximating it with a wave expression and extracting it from the data. The amplitude of this variation is large enough to mask changes produced during geomagnetic storms. To remove this periodicity, we approximate the induced variation with a main period of $648 \mathrm{~h}$ and first two harmonics:

$$
\begin{aligned}
\mathrm{RTECW}= & \mathrm{RTEC}-\left\{a+\sum_{i=1}^{2} b_{i} \cos \left(i \frac{2 \pi}{648}\left(t-t_{0}\right)\right)\right. \\
& \left.+c_{i} \sin \left(i \frac{2 \pi}{648}\left(t-t_{0}\right)\right)\right\} .
\end{aligned}
$$

$a$ is the average offset, the amplitudes are $\sqrt{b i^{2}+c i^{2}}$ and the phases equal to $\tan \frac{b i}{c i}$. The expression (2) is applied to the whole data set, for each month separately, to avoid seasonal smoothing; $t_{0}$ is the hour of the beginning of each month. Figure 1a shows the variation of TEC and the 27-day median reference TEC at geographic grid point $\left(50^{\circ} \mathrm{N}, 15^{\circ} \mathrm{E}\right)$. Then we calculate the power spectral densities of TEC, RTEC and RTECW by virtue of a Matlab signal processing toolbox, using the Welch's method. Figure $1 \mathrm{~b}$ shows the power spectra distribution of TEC, RTEC and RTECW. It is seen that through the above process the components with long periods and diurnal variations have been removed in the RTECW. The RTEC values for the interval 1999-2001 and the wave approximation RTECW are shown in Fig. 1c. It is seen that the offset, amplitudes, and phases change significantly from month to month. The inclusion of the first two harmonics in Eq. (2) is aimed to improve the fitting, because the observed periodicity is not pure sinusoidal. As seen in the figure, harmonic components fit the data fairly well, which can, at most, eliminate the false deviation of the 27 days, which may disturb the real storm response. Though the above process may actually remove the intrinsic 27 -day periodicity, which concerns corotating solar wind streams and recurrent geomagnetic activity, we believe the effect is not significant. During the solar maximum, there are considerable 15-20 magnetic storms associated with interplanetary coronal mass ejections (ICME) which may obscure the 27-day periodicity of the magnetic storms associated with the corotating interaction regions (CIRs). Furthermore CIR-generated magnetic storm always has an elongated recovery phase which is characterized by continuous AE activity that can last for up to 27 days (Tsurutani et al., 2006). This may also disturb the 27-day period appearing in the ionosphere. Actually, we have reproduced the results without removing the harmonic component. No significant difference was found in the morphology of the ionospheric storm results.

We are not ready to follow the procedure employed by Field and Rishbeth (1997) to study the TEC storms, because the AC/DC analysis performed by Field and Rishbeth (1997) to derive seasonal and local time variations has certain deficiencies. For example, in their study ionosonde data were binned for quiet $\left(A_{p}<7\right)$ and disturbed $\left(A_{p}>30\right)$ conditions. All values were included in this analysis, regardless of whether they were from the times of storm onset, main phase or recovery. This treatment has some drawbacks, if we deal with the TEC data. Most storms occur at medium and high solar activity levels when the background TEC values are large, and the amount of quiet days are relatively larger during the low solar activity year when the background TEC values are low. So the average value may result in a systematic positive effect. Secondly, the daily index $A_{p}>30$ is a strict condition which will allow only about $8 \%$ of the total data set to be considered, which is not proper for the statistical investigation with only 8 -year TEC data. Thirdly, a large negative effect will counteract several small positive effects and vice versa, which is not good for the probability results. To avoid a small value of the negative storm effects and to consider the effect of moderate geomagnetic activities on the ionosphere, we use the normalized cross-correlation function expressed as 


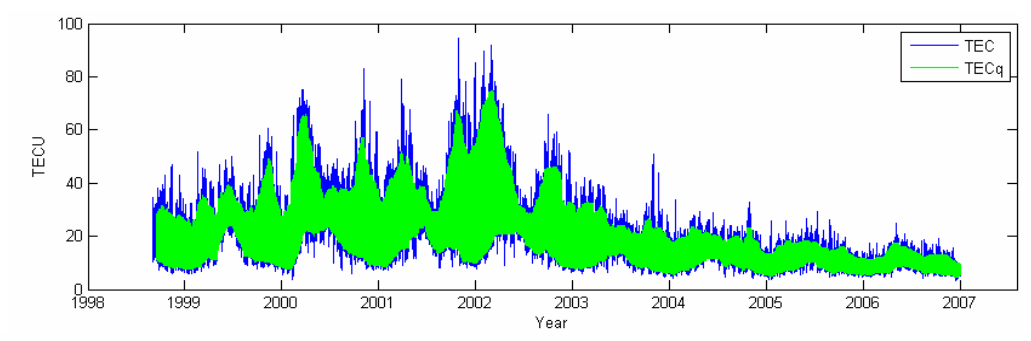

(a)
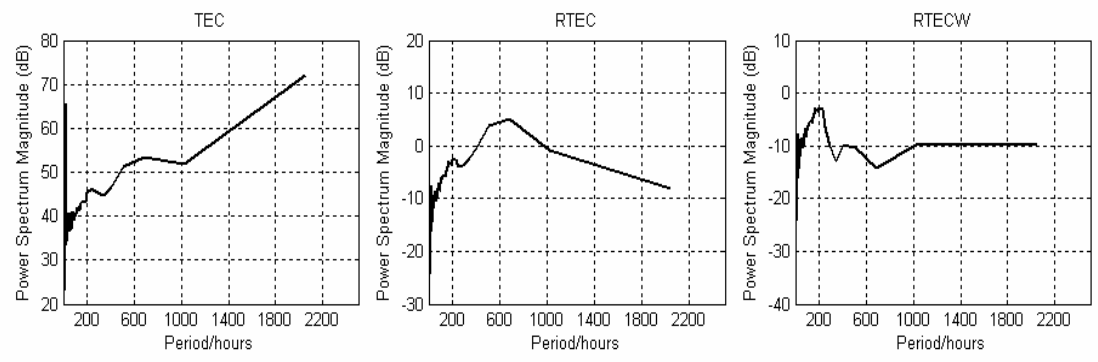

(b)

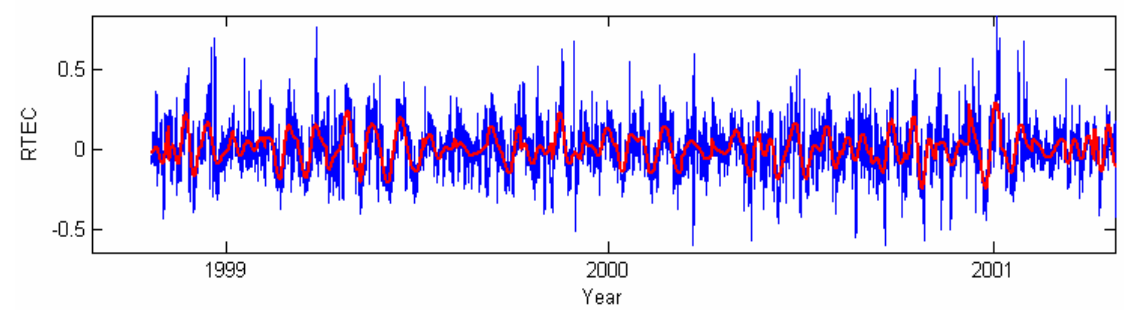

(c)

Fig. 1. (a) Variation of TEC and the 27-day median reference TEC at geographic grid point $\left(50^{\circ} \mathrm{N}, 15^{\circ} \mathrm{E}\right)$. (b) Power spectra distribution of TEC, RTEC and RTECW. (c) RTEC values for the period 1999-2001 and the corresponding wave approximation RTECW.

$c_{x y}(\tau)=\frac{\sum_{i}\left(x\left(t_{i}\right)-\bar{x}\right)\left(y\left(t_{i}+\tau\right)-\bar{y}\right)}{\sqrt{\sum_{i}\left(x\left(t_{i}\right)-\bar{x}\right)^{2} \sum_{i}\left(y\left(t_{i}\right)-\bar{y}\right)^{2}}}$

to study the relationship between the geomagnetic activity and ionospheric response RTEC. Here $x$ and $y$ represent any two time series of data ( $x=y$ yields the auto-correlation), and $\tau$ is the time shift (lag) between any two moments for which the respective values of $x$ and $y$ are cross-correlated. The level of geomagnetic activity can be well denoted by 1 -h interpolated $a_{p}$ index.

The following step is to define a storm event and make a correlation analysis between the $a_{p}$ index and RTEC. As shown in Fig. 2a, there are fairly a number of active geomagnetic activities during days 241-317 of the year 1998 . Many of them present small short-duration peaks that should be caused by the substorms. We used a low-pass Butterworth filter with a window length of $12 \mathrm{~h}$ to smooth the disturbances and to ensure that the geomagnetic disturbances are long lasting. As shown in Fig. 2a, the event between two minimums (circle) whose filter $a_{p} \geq 25$ is considered. The data of the disturbed periods ( 843 events) account for about $28 \%$ of the total data set. The left panel of Fig. $2 \mathrm{~b}$ gives an example of a length of magnetic disturbance and the associated negative ionospheric response RTECW, as well as their cross-correlation function. The right panel shows the situation that causes the positive effect. We record the maximum and minimum values of the cross-correlation coefficient when $\tau \geq 0$. We only keep the maximum or minimum whose absolute value is larger. Then we make statistical results of this maximum and minimum in summer, winter and equinox. We define January, February, December and the second half of November as the winter season (Northern Hemisphere), June, July, August and the second half of May as the summer season, and the rest of the months as the equinox season. This definition is given because many cases show ionospheric storm behavior at the transition month, which manifests a strong seasonal dependence. Take the grid point $\left(50^{\circ} \mathrm{N}, 15^{\circ} \mathrm{E}\right)$, for example, as displayed in Fig. $2 \mathrm{c}$. The negative effects are more often seen in the northern summer (totally 189 events) and the positive effects are most evident at winter (190 events), and the two effects tend to be neutralized in the equinox (464). 


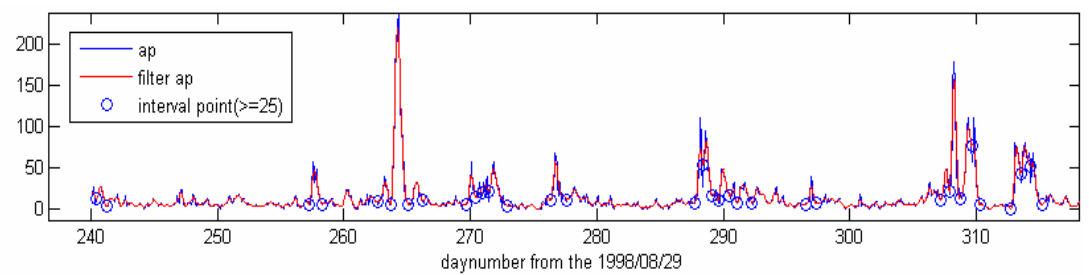

(a)
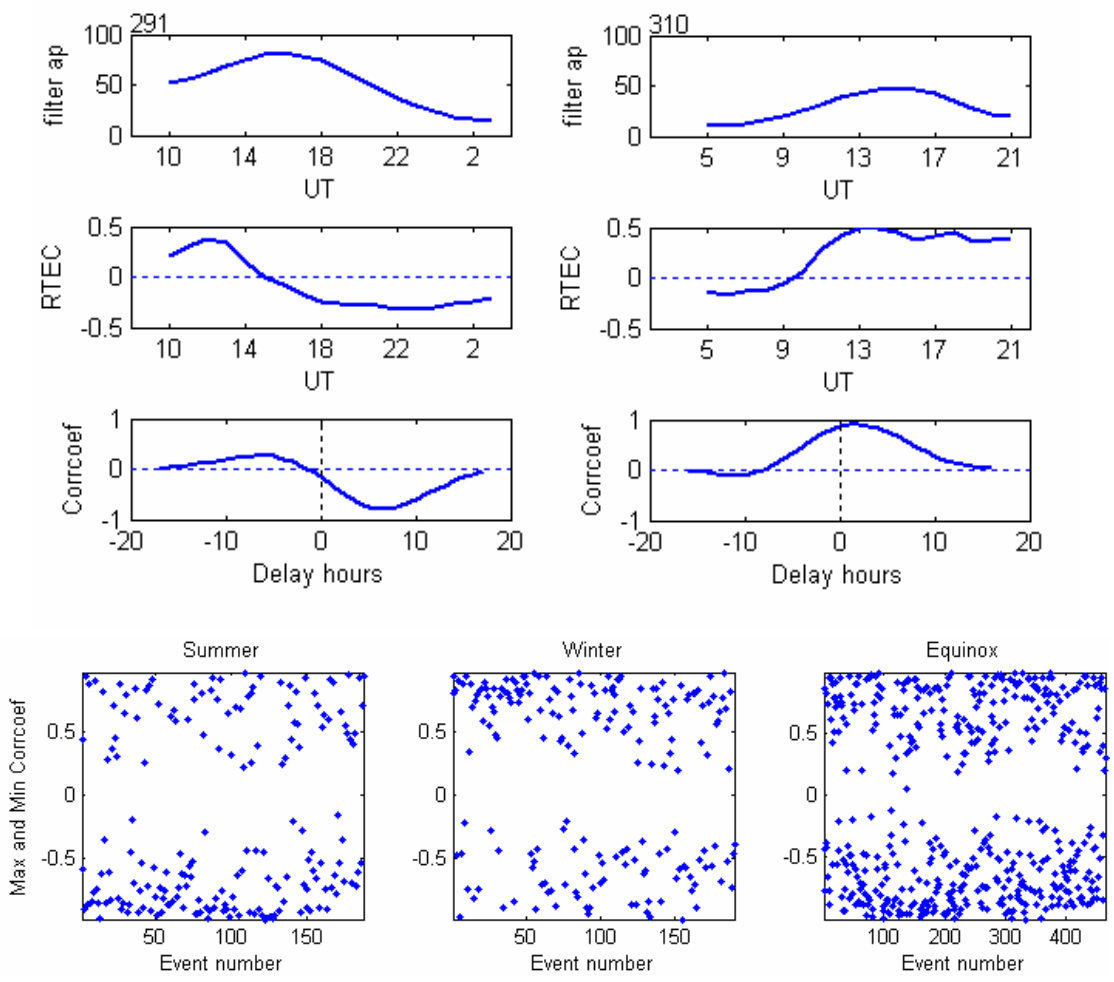

(c)

Fig. 2. (a) Geomagnetic activities during 241st-317th days of 1998 (b) Examples of a length of magnetic disturbance and associated negative and positive ionospheric response RTEC, as well as their cross-correlation functions. (c) Maximum and minimum value of cross-correlation coefficient when $\tau \geq 0$ for the grid point $\left(50^{\circ} \mathrm{N}, 15^{\circ} \mathrm{E}\right)$ in the northern summer, winter and equinox seasons.

\section{Results of analysis}

3.1 Global distributions of seasonal and local time variations of the storm effects

Globally, we sum all the maxima and minima at summer, winter and equinox seasons, as shown in Fig. 3. The upper panel of Fig. 3 illustrates the distribution of the amplitudes of the negative ionospheric response. It is obvious that the negative ionospheric response has a clear seasonal dependence. The negative value is more pronounced in the summer hemisphere than in the winter hemisphere. Furthermore, in the summer season, a large negative value of the Northern Hemisphere in the near-pole (magnetic) longitudes between $-60^{\circ}--120^{\circ}$ can more likely reach the lower latitudes than that of the $60^{\circ}-120^{\circ}$ and the situation is reverse in the winter season for the Southern Hemisphere, which manifests the geomagnetic preference of the negative phase propagation.
This longitude asymmetry is more evident in the Southern Hemisphere, which might be related to the larger offset between the magnetic pole and geographic pole in the Southern Hemisphere than in the northern one.

A positive response also shows a seasonal dependence but this is not as evident as in the negative phase. As displayed in the bottom panel of Fig. 3, the positive effect is much more pronounced at the auroral oval area in the winter hemisphere than in the summer hemisphere, especially for the winter season. In the winter season, the positive phase at middle and low latitudes is more pronounced in the winter hemisphere than in the summer hemisphere. However, in summer, the difference between the two hemispheres is not so evident. Generally, it is shown that a large positive value mainly concentrates at magnetic latitudes $20^{\circ}-60^{\circ}$, where wind-induced uplifting is more effective, except for some areas in the high latitudes which may suggest that they are caused by particle precipitation or other mechanisms. 

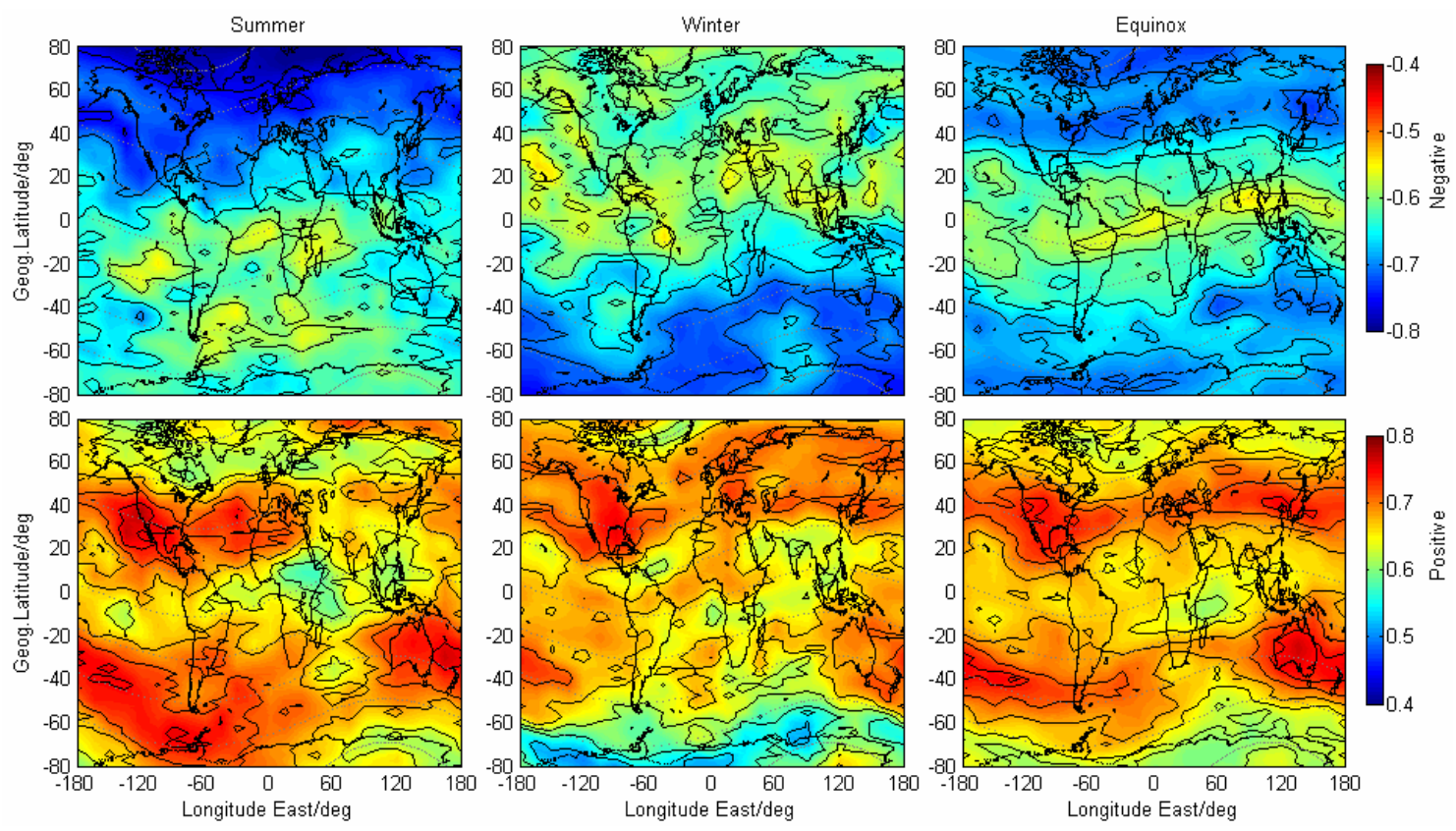

Fig. 3. Global geographic distributions of the amplitudes of the negative and positive ionospheric storm effects.
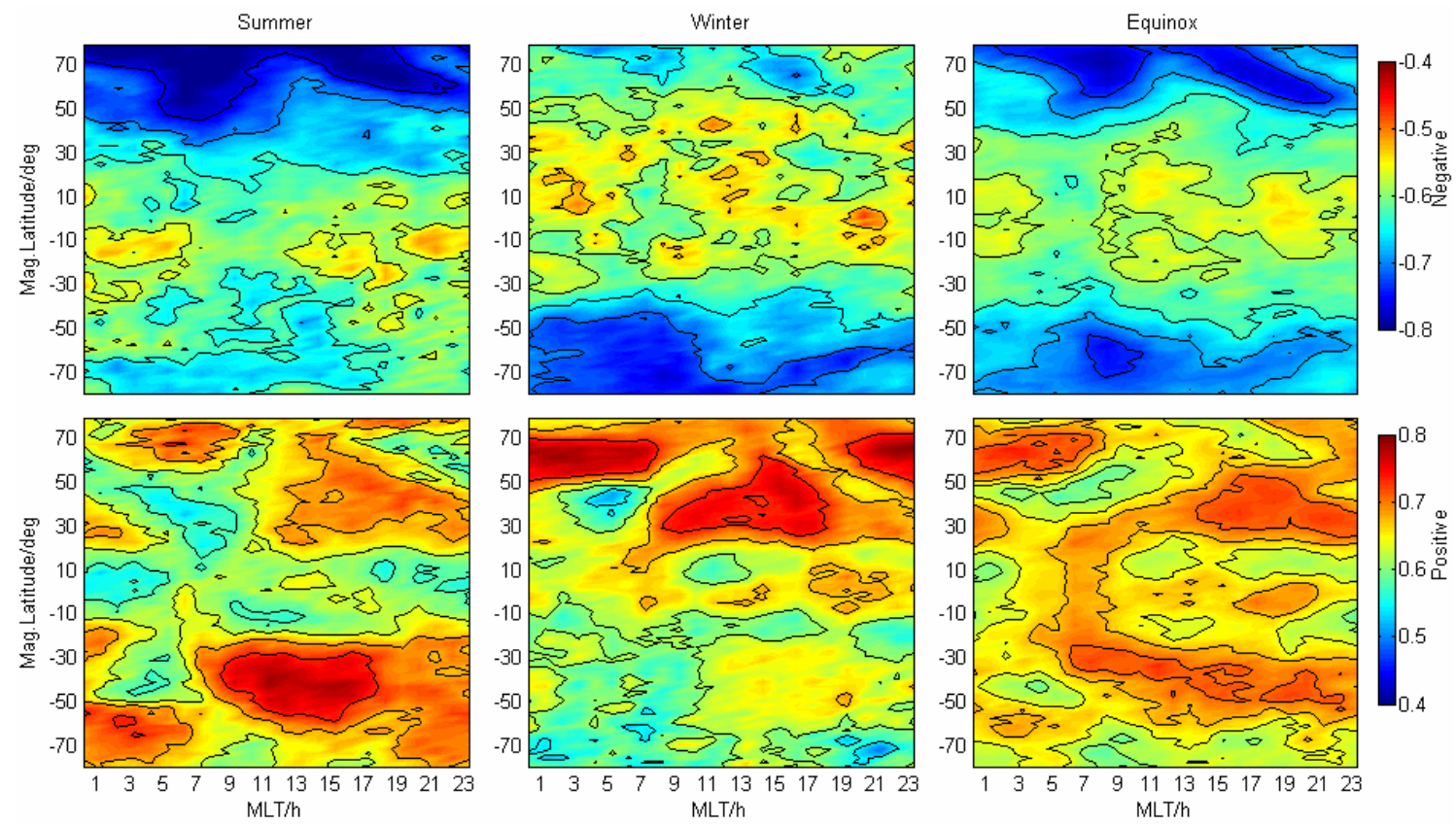

Fig. 4. Global distribution of the amplitudes of the negative and positive ionospheric storm effects in the MLAT vs. MLT frame.

For our purpose in constructing TEC maps, we follow the works of Codrescu et al. (2001) and Jee et al. (2004) to estimate the TEC maps in the plane of magnetic local time (MLT) vs. magnetic latitudes (MLAT). Thus, we first transform the geographic longitude and latitude into MLT (00:00 24:00) and MLAT $\left(-80^{\circ} \sim 80^{\circ}\right)$, and then divide the MLT vs. MLAT plan into mesh grids with grid length
$\mathrm{dMLT}=0.5 \mathrm{~h}$ and $\mathrm{dMLAT}=2.5^{\circ}$. We calculate the average TEC in each bin as the grid TEC values. Then following the procedure described in Sect. 2, we obtain a magnetic local time distribution of the negative and positive storm effects. As shown in the upper panel of Fig. 4, the diurnal variation generally shows that a maximum negative effect appears during the post-midnight and morning sectors in the 
summer hemisphere. With increasing latitudes the depression becomes larger and wider, and is least evident during 11:00-17:00 MLT at middle latitudes. These results resemble the local time distribution of negative phase for $N m \mathrm{~F} 2$ in the previous studies (e.g. Wrenn et al., 1987; Field and Rishbeth, 1997). Positive effects are shown to be separated in latitude, as displayed in the bottom panel of Fig. 4. At higher latitudes, centered at $60^{\circ}$, this is evident during the nighttime, persisting from 21:00 MLT to 07:00 MLT. At middle and low latitudes, centered at $\pm 30^{\circ}-50^{\circ}$, it is most pronounced during 09:00-17:00 MLT in the winter hemisphere. In summer and equinox, the positive phase remains fairly strong and extends to the post-midnight sector. Comparing the positive effect of the summer season with that of the winter season, nighttime auroral enhancement is more pronounced in the Northern Hemisphere than in the Southern Hemisphere, and this is also true for the equinox.

\subsection{Evolutionary characteristics of storm-time TEC under different local times}

The above analysis gives the geometric distribution of the amplitudes of the positive and negative effects when there is an impulsive magnetic disturbance at the auroral area. Now we would like to study the evolutionary behavior of the ionospheric responses to the magnetic disturbances under different local times. Here we choose the main phase onset (MPO) of the storm instead of the storm sudden commencement (SSC) as the definition of the start of the storm. Statistical results show that SSC is not an essential part of magnetic storms (e.g. Loewe and Prölss, 1997). There are several hours of delay or more between SSC and MPO in some storm cases when a long initial phase exists. To define the MPO we have checked both $\mathrm{AE}$ and IMF $B_{z}$ indices because the main phase is often associated with a large burst of $\mathrm{AE}$ and a major southward turning of $B_{z}$. Thomas and Venables (1966) found that the F layer perturbations are not necessarily "turned on" at the time of the SSC but rather at the time of MPO. The sharp decrease in the horizontal component of the global geomagnetic field (or equivalently in the $D_{s t}$ index) marks the intensification time of a geomagnetic storm. The penetration of electric fields and the onset of auroral input occur most strongly after MPO. During the more than 8-year period, 200 storm events with both sudden and gradual storm commencements, whose $D_{s t} \leq-50 \mathrm{nT}$, have been selected (Gonzalez et al., 1994). Note that all the events should have a clear main phase and recovery phase, and only the main phase of the first storm will be considered if there are multi-storms occurring continuously. The number of storm events, as well as their MPO universal time distributions, are given in Fig. 5a. Then we group longitude into 4 groups on the condition that their local time of the MPO is 00:00, 06:00, 12:00 and 18:00 LT, respectively. A superposed epoch analysis is conducted to produce an average pattern of total events.
Figure $5 \mathrm{~b}$ illustrates the overall pattern of ionospheric response for different local times in a 72-h storm period. We will describe the ionospheric responses for $0-12,12-36$ and 36-72 $\mathrm{h}$ after the MPO.

\subsection{1 $0-12 \mathrm{~h}$}

It is shown that ionospheric behaviors at four local time sectors show distinct differences during the first $12 \mathrm{~h}$ after the onset of the storm main phase. For the longitudes when $\mathrm{MPO}=06: 00 \mathrm{LT}$, the storm response is characterized by a prolonged positive TEC value $(\sim 18 \mathrm{~h})$ between magnetic latitudes $\pm 20^{\circ}-50^{\circ}$ following sunrise. This long-lived positive phase may result from the combined effects of wind-lifting, neutral composition changes, prompt penetration and disturbance dynamo electric fields, according to the statistical results of Fejer and Scherliess (1995). For the longitudes when $\mathrm{MPO}=12: 00 \mathrm{LT}$, the storm response is characterized by a stronger positive TEC value which has a tendency to propagate from high-middle latitudes to low latitudes, compared with the situation MPO=06:00 LT. During the sharp decrease stage of $D_{s t}$, a strong southward component of IMF $B_{z}$ and a large enhancement of auroral electrojet currents exist, which is favorable for the magnetospheric convection electric fields to penetrate to the low latitudes. The prompt penetration electric field effect tends to be maximized during 18:00-22:00 LT which often produces the super-fountain effect during the intense storms (Greenspan et al., 1991; Fejer and Scherliess, 1995; Basu et al., 2001; Tsurutani et al., 2004). A strong positive phase in TEC at middle latitudes can also be associated with a "dusk effect" in that TEC increases significantly in the afternoon and evening hours, with large enhancements seen earlier at higher latitudes. The "dusk effect" is often observed in the middle latitudes in North America (Mendillo and Klobuchar, 1975; Foster, 1993; Buonsanto et al., 1995), which was suggested to be caused by a combination of mechanisms, including a TAD, advection of highdensity plasma from lower latitudes, and neutral composition changes.

As for the longitudes when $\mathrm{MPO}=18: 00 \mathrm{LT}$, a positive phase is shown to be separated at around magnetic latitude $\pm 40^{\circ}$. There is a very strong local positive phase centered at 00:00 LT at around magnetic latitude $\pm 60^{\circ}$ with its lower boundary at magnetic latitudes $\pm 50^{\circ}$, where the northern one is obviously more evident than the southern one. This effect should be caused by strong particle precipitation from the magnetosphere when the $D_{s t}$ index reaches its minimum, which means that the magnetosphere is most disturbed. This strong positive phase is shown to be embedded in the negative phase which has been propagated from high latitudes to low latitudes from the pre-midnight time. There is, meanwhile, a moderate positive effect at low latitudes around 20:00-02:00 LT. This could be produced by the combined effect of prompt penetration and disturbance dynamo electric fields, according to the results of Fejer and Scherliess 


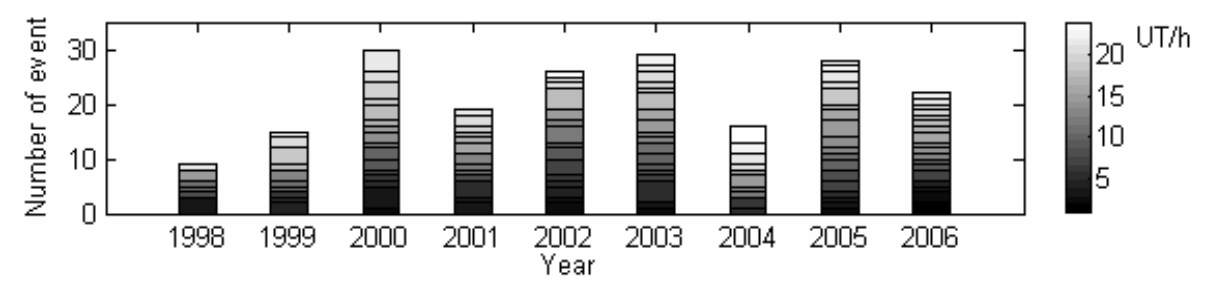

Fig. 5a. Numbers of the storms per year, as well as their universe time distribution.
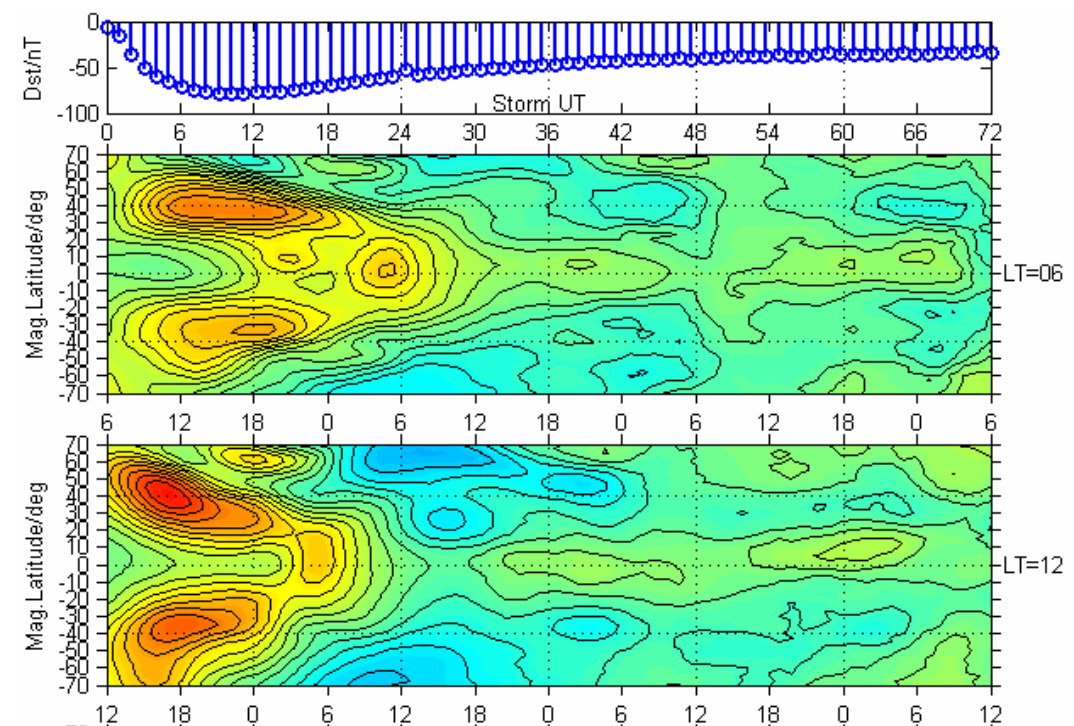

RTEC
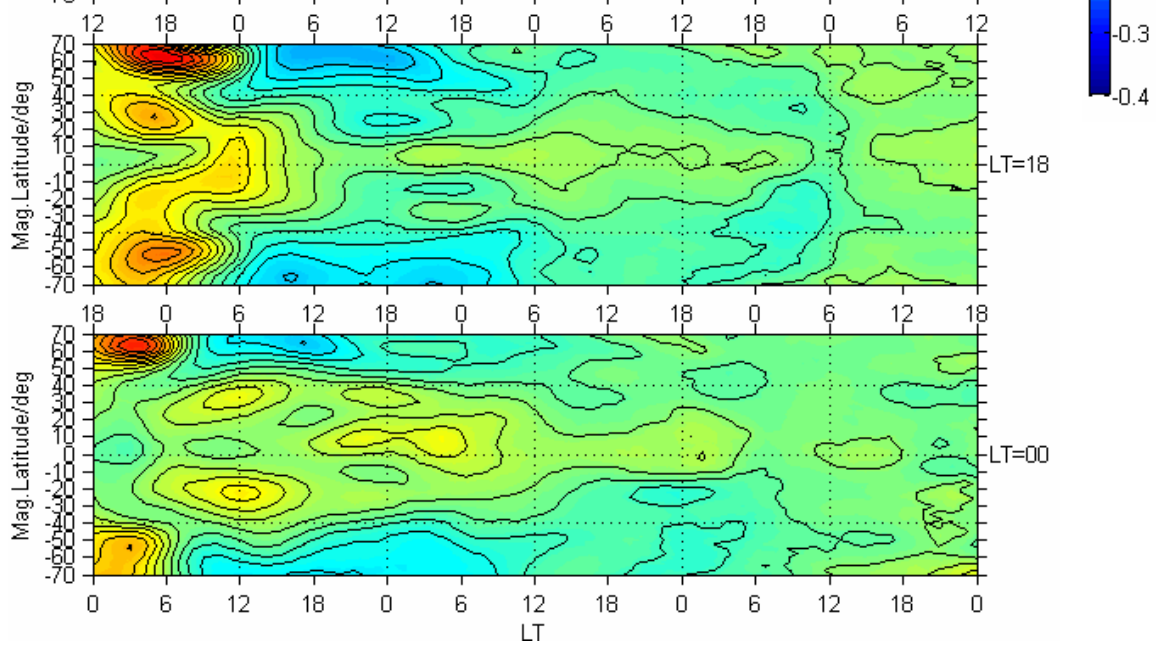

Fig. 5b. The overall pattern of ionospheric response for different local times ( $\mathrm{SC}=06: 00,12: 00,18: 00$ and 00:00 LT) during a 72-h storm period under the condition $D_{s t} \leq-50 \mathrm{nT}$.

(1995). The low-latitude sunrise enhancement, which actually persists from 03:00-09:00 LT, is shown to emerge first for the $\mathrm{MPO}=18: 00 \mathrm{LT}$ and later for $\mathrm{MPO}=12: 00$ and 06:00 LT and last for MPO=00:00 LT. The cause of this notable effect is assumed to be involved with dynamic effects. The plasma seems to be pushed toward the equator to accumulate a hunch. For the longitudes when MPO=00:00 LT, the ionospheric response during the main storm phase is characterized by symmetric auroral enhancements at high latitudes, followed by a TEC depletion being confined at midhigh latitudes. As we can see, the negative phase propagates to the magnetic latitudes $\pm 40^{\circ}$ earliest for the situation $\mathrm{MPO}=00: 00 \mathrm{LT}$ and then $\mathrm{MPO}=18: 00$ and 12:00 LT, and last for MPO=06:00 LT. After sunrise in the middle-low latitudes 
the positive phase just appears but is less significant than the other three situations. This supports the idea that a strong positive phase produced by the first strong equatorward wind surge during the main phase of storm seldom appears in the darkness, due to a lack of production rate. However, if a positive phase develops in the sunlight sector and the region rotates into darkness, the feature persists into the night.

\section{$3.2 .2 \quad 12-36 \mathrm{~h}$}

During the first stage of the recovery phase of the storm, the middle and high latitude areas predominate with a strong negative phase which is shown to move back and forth in latitudes under the control of background wind diurnal variations. Auroral enhancements for the situations $\mathrm{MPO}=06: 00$ and 12:00 LT are not as strong as those of the situation $\mathrm{MPO}=18: 00$ and 00:00 LT during the main phase stage. Meanwhile, at low latitudes, there are moderate TEC abatements at equatorial ionization anomaly regions during 12:00-00:00 LT for both the situations MPO=12:00 and 18:00 LT. The work of Scherliess and Fejer (1997) has shown that the equatorial downward drifts are evident during 12:0016:00 LT at about 20-24 $\mathrm{h}$ after the storm commencement. So the suppression of the fountain effect caused by the disturbed dynamo electric fields can only partly explain the negative phase at the EIA region. Besides the electric fields, another way to modify the equatorial anomaly is through wind-induced drifts. As has been pointed out by Burge et al. (1973), equatorward-directed winds will oppose the poleward transport of ionization along the magnetic fields. This will hinder the formation of the equatorial anomaly and generate negative storm effects in the anomaly crest regions and positive storm effects near the equator. Model calculations by Rüster and King (1976) confirm the validity of this concept. They note that without the fountain effect, equatorward-directed winds will increase the ionization density, as is the case at middle latitudes. This tendency prevails down to about $20^{\circ}$ magnetic latitudes, where a changeover takes places.

For the situation MPO=00:00 LT, the evolution of the positive phase seems to reproduce the process that appears in the main phase for the situation MPO=06:00 LT, except that the magnitude of the daytime positive effect is less pronounced, which manifests that the intensity of the equatorward wind or disturbed electric field is less than those during the main phase of the storm.

\section{$3.2 .3 \quad 36-72 \mathrm{~h}$}

There is a prolonged TEC positive phase effect in the equatorial region accompanied by a weak negative phase at middle latitudes. This could be the result of global composition changes. The idea comes from the notion that the divergence and upwelling of the polar upper atmosphere during a storm could set up a Hadley-type circulation cell which pro- duces its convergence and downwelling in the low and middle latitudes (e.g. Mayr et al., 1978; Rishbeth et al., 1987; Burns et al., 1995). The downwelling of the atmosphere causes a decrease in molecular gases (or a decrease in the $\mathrm{O}^{+}$loss rate) in the $\mathrm{F}$ region and induces a positive storm effect. Using the MSISE-90 semiempirical model, Field and Rishbeth (1997) demonstrated increases in [O/N2] at low latitudes with increasing $A_{p}$ values. Outputs from global first principle models also reveal decreases in the mean air mass (i.e. increases in $[\mathrm{O} / \mathrm{N} 2]$ ) in the previous downwelling regions during the recovery phase of the storm, particularly in the winter hemisphere (e.g. Fuller-Rowell et al., 1994, and references therein).

\subsection{Dayside longitude effects}

To reveal whether the TEC storm has a longitudinal difference, we separate longitude into three sectors: the Asian region $\left(90^{\circ}-165^{\circ}\right)$, American region $\left(-120^{\circ}--45^{\circ}\right)$ and European region $\left(-15^{\circ}-60^{\circ}\right)$. For aach sector a superposed epoch analysis is performed for the midday condition $(\mathrm{MPO}=12: 00 \mathrm{LT})$. As shown in Fig. 6, the longitude difference is seen clearly during the main phase of the storm. The magnitude of the positive phase is most significant in the American region than that in the other two regions. This is consistent with recent observations which show that superfountain effects, resulting in several times growth of TEC at low latitudes, occur frequently in the American longitude (Greenspan et al., 1991; Basu et al., 2001; Tsurutani et al., 2004; Mannucci et al., 2005; Zhao et al., 2005). The storminduced eastward electric field seems to be exaggerated at this area. Table 1 illustrates the storm number distribution according to $D_{s t}$ intensity and season; the sum of the numbers of strong and severe storms $\left(D_{s t} \leq-100 \mathrm{nT}\right.$; Gonzalez et al., 1994) is close at all three sectors. Another longitude difference is that the southern midnight auroral enhancement disappears at the American sectors in comparison with those at the other two sectors. We assumed this to be caused by the relative weak magnetic field at the southern polar region at this longitude sector. Energetic particles tend to precipitate deeper into the atmosphere at low altitudes where the recombination rates are larger, which may reduce the ionized density. Moreover, an increase in molecular air, due to thermal expansion, will also reduce the plasma density at higher altitudes. Undoubtedly, more observational results need to be done to uncover the real mechanism. The third evident longitude difference occurs on the third day of the storm after 18:00 LT, which shows an enhancement of the EIA at the equatorial region for the American sector and suppression of the EIA at the Asian and European sectors.

The outstanding features of the ionospheric storm at American longitudes, which are near the South Atlantic geomagnetic anomaly (SAMA), probably indicate a geomagnetic influence on the storm's ionospheric behavior. The trapped and azimuthally drifting energetic particles, 

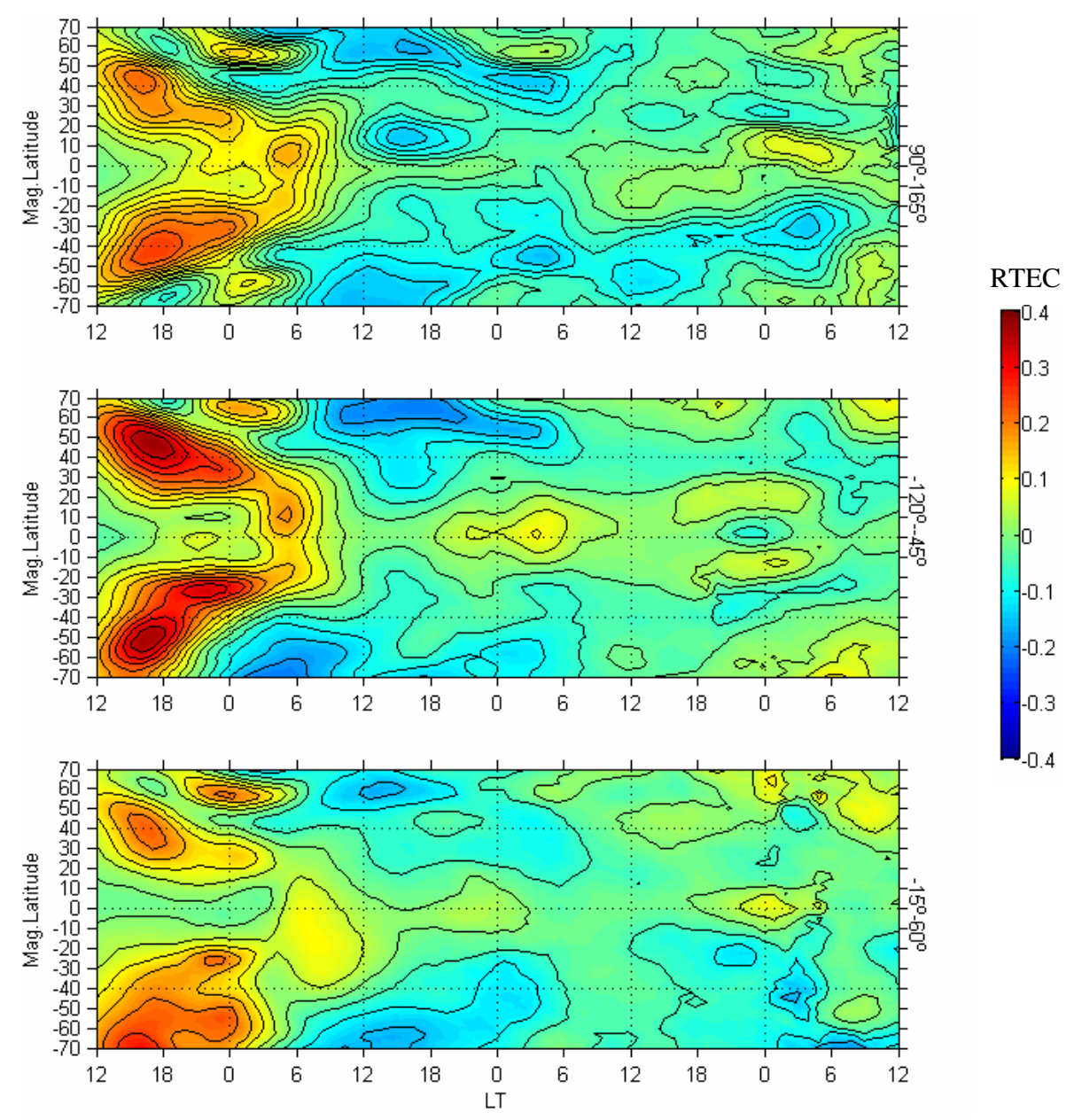

Fig. 6. Storm-time ionospheric evolution at three sectors: Asian region $\left(90^{\circ}-165^{\circ}\right)$, American region $\left(-120^{\circ}--45^{\circ}\right)$ and European region $\left(-15^{\circ}-60^{\circ}\right)$ during daytime for $\mathrm{MPO}=12: 00 \mathrm{LT}$.

Table 1. Storm number distribution according to $D_{s t}$ intensity and season.

\begin{tabular}{|c|c|c|c|c|c|c|c|c|c|c|c|c|}
\hline \multirow[b]{2}{*}{$\mathrm{MPO}=12: 00 \mathrm{LT}$} & \multicolumn{3}{|c|}{ Summer-north } & \multicolumn{3}{|c|}{ Winter-north } & \multicolumn{3}{|c|}{ Equinox } & \multicolumn{3}{|c|}{ total } \\
\hline & As & $\mathrm{Am}$ & $\mathrm{Eu}$ & As & $\mathrm{Am}$ & $\mathrm{Eu}$ & As & $\mathrm{Am}$ & $\mathrm{Eu}$ & As & $\mathrm{Am}$ & $\mathrm{Eu}$ \\
\hline$-100<D_{s t} \leq-50 \mathrm{nT}$ & 6 & 6 & 6 & 8 & 9 & 6 & 16 & 20 & 14 & 30 & 35 & 26 \\
\hline$-200<D_{s t} \leq-100 \mathrm{nT}$ & 2 & 3 & 3 & 2 & 1 & 3 & 15 & 9 & 9 & 19 & 13 & 15 \\
\hline$\leq-200 \mathrm{nT}$ & 1 & 1 & 1 & 0 & 0 & 1 & 3 & 4 & 0 & 4 & 5 & 2 \\
\hline Total & 9 & 10 & 10 & 10 & 10 & 10 & 34 & 33 & 23 & 53 & 53 & 43 \\
\hline
\end{tabular}

bouncing between hemispheres, come deeper down into the atmosphere, owing to the low field intensity over SAMA (in conservation of its second adiabatic invariant), thereby interacting with the dense atmosphere, resulting in ionization production. Past observations using a variety of instruments, such as vertical sounding ionosondes, riometers and VLF receivers, have provided evidence of the enhanced ionization due to energetic particle precipitation in the ionosphere over Brazil (Abdu, 2005). The extra ionization at E- layer heights could produce enhanced ionospheric conductivity within and around the SAMA region. The energetic particle ionization source that is operative even under "quiet" conditions can undergo significant enhancements during magnetospheric storm disturbances, when the geographic region of enhanced ionospheric conductivity can extend to magnetic latitudes closer to the equator where the magnetic field line coupling of the $\mathrm{E}$ and $\mathrm{F}$ regions plays a key role in the electrodynamics of the equatorial ionosphere. Second polarization 
electric fields develop in the vicinity of a conductivity gradient when an external electric field is imposed. Given an imposed upward/poleward electric field, the conductivity gradients at the edge of the SAMA would have contributed to the development of eastward electric fields and upward drifts. This is probably the reason why the "super fountain" effect always occurs at the American longitude areas (Greenspan et al., 1991).

\section{Discussion and conclusion}

Seasonal variations of an F-region storm have long been accepted to be caused by the change in $[\mathrm{O} / \mathrm{N} 2]$ that is associated with large-scale storm wind surges superimposed on the normal summer-to-winter thermospheric circulation (Duncan, 1969). Numerical computations suggest that the prevailing summer-to-winter circulation at solstice transports the molecular-rich gas to middle and low latitudes in the summer hemisphere over a day or two following the storm. In the winter hemisphere, poleward winds restrict the equatorward movement of the composition bulge zone. In winter middle latitudes a decrease in molecular species, associated with downwelling, persists and produces the positive storm (Fuller-Rowell et al., 1994). The TEC storm resembles the seasonal feature of $N m \mathrm{~F} 2$, which shows that a negative phase occurs with high probability in the summer hemisphere and a positive phase is shown to be more prominent in the winter hemisphere. A similar result has also been described by Mendillo (2006), as shown in his Fig. 21. It should be noted that the large negative phase at the post-midnight sector in the equinox in his figure should be caused by the migration of a middle latitude trough moving toward lower latitudes. Furthermore, the distribution of the storm effects is under the control of the geomagnetic configuration, which shows that the negative phase is more pronounced in the nearpole region, especially obvious for the Southern Hemisphere. These characteristics agree with model simulations of FullerRowell et al. (1994), which show that the global wind surge has a preference for the night sector and for the longitude of the magnetic pole. The composition bulge with enriched molecular air can be carried to lower latitudes through this wind. The results, however, show that the longitude response of the negative phase in the Southern Hemisphere is more asymmetric than that of the Northern Hemisphere. Possibly one explaination of this feature can be attributed to the moving of the magnetic pole. It is known that the magnetic pole is continuously moving northwest, with the northern one shifting from $\sim 76^{\circ}$ fifty years ago to the present $\sim 82^{\circ}$, and the southern one from $\sim-68^{\circ}$ to $\sim-64^{\circ}$. The changing position of southern magnetic pole will result in a lower boundary of auroral oval in the Australian sector and a higher boundary in the South American sector, and thus increase the longitude difference of ionospheric response, if the geometry of magnetic field is greatly influenced by the shifting of the magnetic pole, while the moving of the north magnetic pole reduces the difference between the near-pole and far-pole regions. To further confirm this expalination, it is necessary to resort to long-term history ionosonde data and other factors may need to be considered, as well.

The local time dependence of the negative phase of the TEC storm can be explained by the composition bulge that was modulated by the diurnal variation of the wind fields (Fuller-Rowell et al., 1994). In the post-midnight and early morning sectors with reduced ion drag, the storm-intensified winds blow equatorward, thus enhancing the molecular concentration at mid-latitudes and producing a maximum molecular concentration as the wind turns poleward in the morning. A positive phase is shown to be separated into several parts, according to different local times. For the TEC storm, an intense positive phase, due to the particle precipitation, is more prominent than the F-region storm in the nighttime at the auroral area. In the high latitudes or auroral area, the positive storm effect during the night, as illustrated in Fig. 4, may probably suggest that it is caused by the intense particle precipitation, especially in winter. Lower energy electrons $(<1 \mathrm{keV})$ are often observed to precipitate from the plasma sheet, from the magnetosheath, and from the magnetopause boundary layer (Turunen and Liszka, 1972; Labelle et al., 1989; Schumaker et al., 1989). A comprehensive survey (Newell et al., 1996) describes a number of satellite measurements of the flux of precipitating electrons as a function of magnetic local time. Electron precipitation associated with discrete auroral arcs occurs predominately in the 18:00-24:00 MLT sector. Past observation shows that during magnetic disturbed conditions, particle precipitation will intensify and expand, and cause positive storm effects at higher and lower latitudes (Essex and Watkins, 1973; Buonsnato et al., 1979). Figure 4 shows that a winter auroralparticle-induced enhancement is more intensified than that of the other seasons, which is also illustrated in the results of Mendillo (2006). This can be attributed to the much lower value of the background TEC in the winter nighttime that makes relative change very extraordinary. It should be noted that the magnitude of this positive phase is much higher in the northern auroral oval region than that in the southern one, as shown in Fig. 4 and Fig. 5b. Is this asymmetry related to the geomagnetic field difference for the two hemispheres or is it due to the scarce TEC observations in the southern auroral area? This still remains an open question which is worth further investigation.

In the middle-low latitudes of the Northern Hemisphere, the positive phase after 18:00 LT is more pronounced during the equinox season and after 00:00 LT during the summer season. A similar feature was given by Mendillo (2006), which shows that the midday enhancement due to winds is always there, while the afternoon enhancement, due to a convection of plasma from lower altitudes/latitudes, follows the day length and thus the longevity of solar production (TEC peak enhancements occur later in summer, earlier in winter). 
Ionospheric response in the different local time sectors, with respect to the MPO of the storm, shows a very different process corresponding to the evolution of the magnetic storm, as illustrated in Fig. 5b. The positive phase is shown to be predominant during the first $12 \mathrm{~h}$ of the storm at middle and low latitude, if the local time of MPO is in the daytime. The result is consistent with the observations of Prölss (1993), which suggested that daytime positive storms are attributed to traveling atmospheric-ionospheric disturbances and subsequent changes in the global wind circulation. For the situation $\mathrm{MPO}=12: 00 \mathrm{LT}$ the positive phase is strongest, which may result from combined effects including the "dusk effect" and low-latitude magnetospheric disturbed electric fields during the main phase of the storm. Moreover, the daytime positive storm effect is shown to be more prominent in the American region than that in the Asian and European regions. This could be due to its position near the SAMA region, where the electrodynamic process has been changed due to the energetic particle precipitation. During the later recovery phase of the storm, the low-latitude positive phase could probably be caused by the composition changes produced by the downwelling part of the storm circulation. For all the situations, the TEC storm presents a strong sunrise enhancement (03:00-08:00 LT) at the equatorial area. We assumed this to be attributed to both the combined effect of the electric fields and the wind fields. There is an eastward wind disturbance electric field around the midnight sector and meanwhile, the equatorward wind, which will hinder the formation of the equatorial anomaly, will generate positive storm effects near the equator.

In this paper we derive a global morphology of the TEC storm features by using 8-year JPL GIMs products. The data of 2-h resolution is allowed, obtaining large-scale variations of storm-time behavior. In the future, regional ionospheric storm characteristics will be investigated with high resolution TEC data and we hope to resort to the model simulations to help us in understanding the observed TEC storm features.

Acknowledgements. This research was supported by the National Natural Science Foundation of China (40574071, 40636032) and National Important Basic Research Project (2006CB806306), KIP Pilot Project (kzcx3-sw-144) of Chinese Academy of Sciences.

Topical Editor M. Pinnock thanks E. Astafyeva and another anonymous referee for their help in evaluating this paper.

\section{References}

Abdu, M. A., Sobral, J. H. A., Paula, E. R., and Batista, I. S.: Magnetospheric disturbance effects on the Equatorial Ionization Anomaly (EIA): An overview, J. Atmos. Terr. Phys., 53, 757771,1991

Abdu, M. A., Batista, I. S., Carrasco, A. J., and Brum, C. G. M.: South Atlantic magnetic anomaly ionization: A review and a new focus on electrodynamic effects in the equatorial ionosphere, $\mathrm{J}$. Atmos. Sol. Terr. Phy., 67, 1643-1657, 2005.
Afraimovich, E. L., Kosogorov, E. A., Leonovich, L. A., Palamarchouk, K. S., and Pirog, O. M.: A global picture of electron density disturbances duting the September, 25, 1998 major ionospheric storm as deduced from GPS data, Geomagn. Aeronomy, 42(4), 467-473, 2002.

Aponte, N., Gonzalez, S. A., Kelley, M. C., Tepley, C. A., Pi, X., and Iijima, B. A.: Advection of the equatorial anomaly over Arecibo by small-storm related disturbance dynamo electric fields, Geophys. Res. Lett., 27, 2833-2836, 2000.

Basu, S., Basu, S., Groves, K. M., Yeh, H.-C., Su, S.-Y., Rich, F. J., Sultan, P. J., and Keskinen, M. J.: Response of the equatorial ionosphere in the South Atlantic region to the great magnetic storm of July 15, 2000, Geophys. Res. Lett., 28, 3577-3580, 2001.

Blanc, M. and Richmond, A. D.: The ionospheric disturbance dynamo, J. Geophys. Res., 85, 1669-1686, 1980.

Buonsanto, M. J., Mendillo, M., and Klobuchar, J. A.: The ionosphere at $\mathrm{L}=4$ : Average behavior and the response to geomagnetic storms, Ann. Geophys., 35, 15-26, 1979,

http://www.ann-geophys.net/35/15/1979/.

Buonsanto, M. J.: Ionospheric storms - A review, Space Sci. Rev., 88, 563-601, 1999.

Burge, J. D., Eccles, D. J., King, W., and Rüster, R.: The effects of thermospheric winds on the ionosphere at low and middle latitudes during magnetic disturbances, J. Atmos. Terr. Phys., 35, 617-623, 1973.

Burns, A. G., Killeen, T. L., Deng, W., Carignan, G. R., and Roble, R. G.: Geomagnetic storm effects in the low- to middlelatitude upper thermosphere, J. Geophys. Res., 100, 14673 $14691,1995$.

Cander, L. R.: On the global and regional behaviour of the midlatitude ionosphere, J. Atmos. Terr. Phys., 55, 1543-1551, 1993.

Codrescu, M. V., Beierle, K. L., Fuller-Rowell, T. J., Palo, S. E., and Zhang, X.: More total electron content climatology from TOPEX/Poseidon measurements, Radio Sci., 36, 325-333, 2001

Davies, K.: Recent progress in satellite radio beacon studies with particular emphasis on the ATS-6 radio beacon experiment, Space Sci. Rev., 25(4), 357-430, 1980.

Duncan, R. A.: F-region seasonal and magnetic-storm behaviour, J. Atmos. Terr. Phys., 31, 59-70, 1969.

Essex, E. A. and Watkins, B. J.: Enhancements of ionospheric total electron content in the southern auroral zone associated with magnetospheric substorms, J. Atmos. Terr. Phys., 35, 10151018, 1973.

Essex, E. A., Mendillo, M., Schödel, J. P., et al.: A global response of the total electron content of the ionosphere to the magnetic storms of 17 December and 18 June 1972, J. Atmos. Terr. Phys., 43, 293-306, 1981.

Fejer, B. G. and Scherliess, L.: Time dependent response of equatorial ionospheric electric fields to magnetospheric disturbances, Geophys. Res. Lett., 22, 851-854, 1995.

Feltens, J. and Schaer, S.: IGS Products for the Ionosphere, in: Proceedings of the IGS Analysis Center Workshop, edited by: Dow, J. M., Kouba, J., and Springer, T., pp. 225-232, Darmstadt, 9-11 February 1998.

Field, P. R. and Rishbeth, H.: The response of the ionospheric F2layer to geomagnetic activity: an analysis of worldwide data, J. Atmos. Terr. Phys., 59, 163-180, 1997.

Field, P. R., Rishbeth, H. R., Moffett, J. D., Idenden, W. T., Fuller- 
Rowell, J. G., Millward, H., and Aylward, A. D.: Modeling composition changes in F-layer storms, J. Atmos. Terr. Phys., 60, 523-543, 1998.

Foster, J. C.: Storm time plasma transport at middle and high latitudes, J. Geophys. Res., 98, 1675-1689, 1993.

Foster, J. C., Coster, A. J., Erickson, P. J., Goldstein, J., and Rich, F. J.: Ionospheric signatures of plasmaspheric tails, Geophys. Res. Lett., 29, 1623, doi:10.1029/2002GL015067, 2002.

Fuller-Rowell, T. J., Codrescu, M. V., Moffett, R. J., and Quegan, S.: Response of the thermosphere and ionosphere to geomagnetic storms, J. Geophys. Res., 99, 3893-3914, 1994.

Fuller-Rowell, T. J., Codrescu, M. V., Rishbeth, H., Moffett, R. J., and Quegan, S.: On the seasonal response of the thermosphere and ionosphere to geomagnetic storms, J. Geophys. Res., 101, 2343-2353, 1996.

Gonzalez, W. D., Joselyn, J. A., Kamide, Y., Kroehl, H. W., Rostoker, G., Tsurutani, B. T., and Vasyliunas, V. M.: What is a geomagnetic storm?, J. Geophys. Res., 99, 5771-5792, 1994.

Greenspan, M. E., Rasmussen, C. E., Burke, W. J., and Abdu, M. A.: Equatorial density depletions observed at $840 \mathrm{~km}$ during the great magnetic storm of March 1989, J. Geophys. Res., 96, 13 931-13 942, 1991.

Ho, C. M., Mannucci, A. J., Lindqwister, U. J., Pi, X., and Tsurutani, B. T.: Global ionosphere perturbations monitored by the worldwide GPS network, Geophys. Res. Lett., 23, 3219-3222, 1996.

Ho, C. M., Wilson, B. D., Mannucci, A. J., Lindqwister, U. J., and Yuan, D. N.: A comparative study of ionospheric total electron content measurements using global ionospheric maps of GPS, TOPEX radar, and the Bent model, Radio Sci., 32, 1499-1512, 1997.

Jee, G., Schunk, R. W., and Scherliess, L.: Analysis of TEC data from the TOPEX/Poseidon mission, J. Geophys. Res., 109, A01301, doi:10.1029/2003JA010058, 2004.

Kil, H., Paxton, L. J., Pi, X., Hairston, M. R., and Zhang, Y.: Case study of the 15 July 2000 magnetic storm effects on the ionosphere-driver of the positive ionospheric storm in the winter hemisphere, J. Geophys. Res., 108(A11), 1391, doi:10.1029/2002JA009782, 2003.

Kutiev, I., Watanabe, S., Otsuka, Y., and Saito, A.: Total electron content behavior over Japan during geomagnetic storms, J. Geophys. Res., 110, A01308, doi:10.1029/2004JA010586, 2005.

Labelle, J., Sica, R. J., Kletzing, C., Earle, G. D., Kelly, M. C., Lummerzheim, D. R., Torbert, B., Baker, K. D., and Berg, G.: Ionization from soft electron precipitation in the auroral $F$ region, J. Geophys. Res., 94, 3791-3798, 1989.

Loewe, C. A. and Prölss, G. W.: Classification and mean behavior of magnetic storms, J. Geophys. Res., 102, 14 209-14 213, 1997.

Mannucci, A. J., Wilson, B. D., Yuan, D. N., Ho, C. M., Lindqwister, U. J., and Runge, T. F.: A global mapping technique for GPSderived ionospheric total electron content measurements, Radio Sci., 33, 565-582, 1998.

Mannucci, A. J., Tsurutani, B. T., Iijima, B. A., Komjathy, A., Saito, A., Gonzalez, W. D., Guarnieri, F. L., Kozyra, J. U., and Skoug, R.: Dayside global ionospheric response to the major interplanetary events of October 29-30, 2003 "Halloween Storms", Geophys. Res. Lett., 32, L12S02, doi:10.1029/2004GL021467, 2005.

Matsushita, S.: A study of the morphology of ionospheric storms,
J. Geophys. Res., 64, 305-321, 1959.

Mayr, H. G., Harris, I., and Spencer, N. W.: Some properties of upper atmosphere dynamics, Rev. Geophys. Space Sci., 16, 539$565,1978$.

Mendillo, M. and Klobuchar, J. A.: Investigations of the ionospheric $\mathrm{F}$ region using multistation total electron content observations, J. Geophys. Res., 80, 643-650, 1975.

Mendillo, M.: Storms in the ionosphere: Patterns and processes for total electron content, Rev. Geophys., 44, RG4001, doi:10.1029/2005RG000193, 2006.

Newell, P. T., Lyons, K. M., and Meng, C.-I.: A large survey of electron acceleration events, J. Geophys. Res., 101, 2599-2614, 1996.

Pi, X., Mannucci, A., Lindqwister, U. J., and Ho, C. M.: Monitoring of global ionospheric irregularities using the worldwide GPS network, Geophys. Res. Lett., 24, 2283-2286, 1997.

Prölss, G. W., Brance, L. H., Mayr, H. G., Carignan, G. R., Killeen, T. L., and Klobuchar, J. A.: Ionospheric storm effects at subauroral latitudes: a case study, J. Geophys. Res., 96, 1275-1288, 1991.

Prölss, G. W.: On explaining the local time variation of ionospheric storm effects, Ann. Geophys., 11, 1-9, 1993, http://www.ann-geophys.net/11/1/1993/.

Rishbeth, H., Fuller-Rowell, T. J., and Rees, D.: Diffusive equilibrium and vertical motion in the thermosphere during a sever magnetic storm: A computational study, Planet. Space Sci., 35, 1157-1165, 1987.

Rodger, A. S., Wrenn, G. L., and Rishbeth, H.: Geomagnetic storms in the Antarctic F-region. II. Physical interpretation, J. Atmos. Terr. Phys., 31, 851-866, 1989.

Rüster, R. and King, J. W.: Negative ionospheric storms caused by thermospheric winds, J. Atmos. Sol. Terr. Phys., 38, 593-598, 1976.

Schaer, S., Gurtner, W., and Feltens, J.: IONEX: The IONosphere Map EXchange format Version 1, in: Proceedings of the IGS Analysis Center Workshop, edited by: Dow, J. M., Kouba, J., and Springer, T., pp. 233-247, Darmstadt, 9-11 February 1998.

Scherliess, L. and Fejer, B. G.: Storm time dependence of equatorial disturbance dynamo zonal electric fields, J. Geophys. Res., 102, 24 037-24 046, 1997.

Schumaker, T. L., Gussenhoven, M. S., Hardy, D. A., and Carovillano, R. L.: The relationship between diffuse auroral and plasma sheet electron distributions near local midnight, J. Geophys. Res., 94, 10 061-10 078, 1989.

Szuszczewicz, E. P., Lester, M., Wilkinson, P., Blanchard, P., Abdu, M., Hanbaba, R., Igarashi, K., Pulinets, S., and Reddy, B. M.: A comparative study of global ionospheric responses to intense magnetic storm conditions, J. Geophys. Res., 103, 11665 $11684,1998$.

Titheridge, J. E. and Buonsanto, M. J.: A comparison of northern and southern hemisphere TEC storm behavior, J. Amos. Terr. Phys., 50, 763-780, 1988.

Thomas, L. and Venables, F. H.: The onset of the F-region disturbance at middle latitudes during magnetic storms, J. Atmos. Terr. Phys., 28, 599-605, 1966.

Tsurutani, B. T., Mannucci, A., Iijima, B., et al.: Global dayside ionospheric uplift and enhancement associated with interplanetary electric fields, J. Geophys. Res., 109, A08302, doi:10.1029/2003JA010342, 2004. 
Tsurutani, B. T., Gonzalez, W. D., Gonzalez, A. L. C., et al.: Corotating solar wind streams and recurrent geomagnetic activity: A review, J. Geophys. Res., 111, A07S01, doi:10.1029/2005JA011273, 2006.

Turunen, T. and Liszka, L.: Comparison of simultaneous satellite measurements of auroral particle precipitation with bottomside ionosonde measurements of the electron density in the F-region, J. Atmos. Terr. Phys., 34, 365-372, 1972.

Vlasov, M., Kelley, M. C., and Kil, H.: Analysis of ground-based and satellite observations of F-region behavior during the great magnetic storm of 15 July, J. Atmos. Sol. Terr. Phys., 65, 12231234, 2003.

Wrenn, G. L., Rodger, A. S., and Rishbeth, H.: Geomagnetic storms in the Antarctic F-region. I. Diurnal and seasonal patterns for main phase effects, J. Atmos. Terr. Phys., 49, 901-913, 1987.
Yizengaw, E., Moldwin, M. B., Dyson, P. L., and Immel, T. J.: Southern Hemisphere ionosphere and plasmasphere response to the interplanetary shock event of 29-31 October 2003, J. Geophys. Res., 110, A09S30, doi:10.1029/2004JA010920, 2005.

Yizengaw, E., Moldwin, M. B., Komjathy, A., and Mannucci, A. J.: Unusual topside ionospheric density response to the November 2003 superstorm, J. Geophys. Res., 111, A02308, doi:10.1029/2005JA011433, 2006.

Zhao, B., Wan, W., and Liu, L.: Responses of equatorial anomaly to the October-November 2003 superstorms, Ann. Geophys., 23, 693-706, 2005,

http://www.ann-geophys.net/23/693/2005/. 